\title{
Developing Reading Comprehension through Metacognitive Strategies: A Review of Previous Studies
}

\author{
Mansoor Ahmed Channa ${ }^{1,2}$, Zaimuariffudin Shukri Nordin ${ }^{2}$, Insaf Ali Siming ${ }^{1,3}$, Ali Asgher Chandio ${ }^{1,4}$ \& \\ Mansoor Ali Koondher ${ }^{1}$ \\ ${ }^{1}$ English Language Center, Quaid-e-Awam University of Engineering, Science and Technology, Pakistan \\ ${ }^{2}$ Faculty of Cognitive Sciences and Human Development, University Malaysia Sarawak, Malaysia \\ ${ }^{3}$ Faculty of Science, Technology, and Human Development, UTHM, Malaysia \\ ${ }^{4}$ Faculty of Education, University of Warsaw, Poland \\ Correspondence: Mansoor Ahmed Channa, Faculty of Cognitive Sciences and Human Development, University \\ Malaysia Sarawak, Malaysia. E-mail: mansoor.english@yahoo.com
}

Received: May 6, 2015 Accepted: July 13, 2015 Online Published: July 28, 2015

doi:10.5539/elt.v8n8p181 URL: http://dx.doi.org/10.5539/elt.v8n8p181

\begin{abstract}
This paper has reviewed the previous studies on metacognitive strategies based on planning, monitoring, and evaluating in order to develop reading comprehension. The main purpose of this review in metacognition, and reading domain is to help readers to enhance their capabilities and power reading through these strategies. The researchers reviewed articles, papers, and books related to the field. The studies indicated that the strategies used in reading comprehension are significant. The findings of this study reveal teachers scaffold to develop reading and comprehending abilities of students. This review study would help readers to consider metacognitive strategies as the input to design reading comprehension material and syllabus based on planning, monitoring, and evaluating strategies for students to improve reading skills for learners' better comprehension of the text according to their needs.
\end{abstract}

Keywords: metacognitive, metacognition, strategies, reading, comprehending

\section{Introduction}

The term metacognition was founded by (Flavell, 1979) and can be defined as a knowledge that is based on reasoning related to cognitive occurrences dealing with the certain material. However, the approach of cognitive development (Piaget, 1971) as well as cognitive and learning development (Vygotsky, 1978) exercised greater influence upon Flavell, and both paved a way for him to continue work in the field and found little metacognition problem in the area as, "a largely divided path of research- one for cognitive researchers and other for educators" (Son, 2005). Further, metacognition denotes knowledge involving cognitive processes for careful monitoring and regulating comprehension strategy of readers with certain goals (Flavell, 1976). Flavell (2004) further defined metacognition as an activity used to regulate to some extent of cognitive creativity. However, Brown and Palincsar (1987) defined metacognition is a term that refers to the knowledge of learners by controlling through cognitive methods. Brown and Palincsar (1987) proposed two problems with the term metacognition that include difficulty in judging the difference between Meta and cognitive. Tarricone (2011) explained that metacognitive are the information, its processes, monitoring, and its control for obtaining novel learning. Zimmerman and Moylan (2009) explained metacognitive that denotes to knowledge, its cognizance, and regulation of one's thinking. Different ways are adopted to define metacognition but the best definition for all times to cite by many researchers is Flavell's (1976) theory.

\subsection{Metacognition and Reading Comprehension}

Most studies unveil the differences between good and poor readers. Metacognition is an approach of awareness to readers using different strategies in order to comprehend the material. Baker and Brown (1984) asserted that metacognitive knowledge is the knowledge related to the learners and their use of strategies and tasks in reading activities in class. Baker (2002) suggested that controlling in metacognition refers to self-regulatory efforts of cognitive approach including Baker's (2002) "planning", "efforts", "evaluating", "remedying", and "testing". Comprehending a text is a very complex mental process. 


\section{Method}

This study reviews the literature on metacognitive strategies based on planning, monitoring, and evaluating related to reading outputs. The articles published from 1971 to 2015 were reviewed. The researcher narrowed down the search to the articles, published in peer reviewed journals, and books. The search processing was based on Google Scholar and library to provide a comprehensive and systematic methodology. The investigation option adopted was limited only to articles' titles and related keywords.

\section{Review of Strategies Literature}

Boulware-Gooden et al. (2007) described that metacognitive strategies in terms of reading help students to 'think about thinking' (before, during, and after) they read. Following is the literature reviewed according to the strategies considered for the improvement of reading and comprehending the text.

\subsection{Planning as Metacognitive Strategy}

Researchers like Brown and Palincsar (1982) and Zimmerman and Pons (1986) explained that learning needs the capability of planning for learning strategies. Reading is a three-step pre-reading, reading, and post-reading practice. Accommodating gimmicks incorporate, however are not restricted to, author, title, chapter by chapter list, and front and back spread blurbs (Benchmarkeducation, 2011). Further, Benchmarkeducation (2011) elaborated that pictures, design, headings, and subheadings likewise assume an enormous part in helping readers make surmises about the substance of the content, which are accordingly considered as the piece of the planning procedures. Further, Zimmerman (2008) described that the objective setting is a procedure to be utilized as a part of the planning stage by calling attention to that while setting testing objectives incite the accomplishment of larger amount execution, setting troublesome objectives is not typically regarded valuable in controlling learners' regulation in case of objectives may not seem reachable particularly. Similarly, Ariel, Dunlosky and Bailey (2009) emphasized for students' learning process by means of planning about how to learn with different choices. Moreover, Brown and Palincsar (1982) proposed pre-reading procedures in planning that include surveying and anticipating as the most important systems. At the point when attempting to comprehend, readers need to divide time in order to ensure positive outcomes and for better results. In addition, Schiff and Calif (2004) suggested that planning likewise calls for careful reading of the inquiries for a finer text cognizance.

\subsection{Monitoring as Metacognitive Strategy}

Thiede, Anderson, and Therriault (2003) believed that reading and comprehension need to monitor learners' understanding during reading accurately. Further, they believed that self-regulated behavior in reading can be identified through monitoring the text when it is comprehended by the readers. Thiede, Anderson, and Therriault (2003) further asserted that self-regulated learning models help readers to read the text through "learning for the to-be-learned material" philosophy that needs to form a wish to follow for better comprehension. In this strategy, learners do monitor in order to see in what way material is taken for comprehension. Monitoring is used to evaluate the level of readers. If the level of learning is achieved, the readers do leave more learning. If the desired of learning of the readers is not yet achieved, the readers continue reading till its success (Thiede, Anderson, \& Therriault, 2003). Thiede, Anderson, and Therriault (2003) further states that there is a need of accuracy in monitoring comprehension of students in order to make them independent learners. Independent or self- regulated readers take responsibility of their own reading and monitor their comprehension level. Most readers reread material in order to answer close reading questions. Schiff and Calif (2004) stated that monitoring in reading is implemented for checking intertextual features that include stylistic features, complex sentence features, and markers in order to integrate novel material for reading comprehension. There are other metacognitive strategies including think-aloud, self-questioning, and self-regulating associated for monitoring of learners' reading and comprehension.

\subsubsection{Think-Aloud Strategy}

Newell and Simon (1972) developed this strategy for evaluation comprehension of the students. Block (1986) called this strategy as problem solving for readers to read and comprehend well by participating in reading actively. Think aloud supports readers to learn through this cognitive strategy related to metacognitive strategies to help students for better performance through thinking and comprehending the text. According to Rosenshine and Meister (1992) think-aloud is a scaffolding device for imparting cognitive strategies to make sure of its modeling in comprehension by articulating students' thoughts and their reading loudly to be heard by all peers in class. Further, Rosenshine and Meister (1992) asserted that while learners do practice by questioning through reading task; they are given support by their teachers who model their thinking practices aloud by allowing them to verbalize in the presence of class. Block (1986) considered think-aloud as a strategy to observe the material 
directly for better reading practices. Anderson (1991) illustrated think- aloud practices that students employ this cognitive strategy for summarizing and clarifying difficult material in the class.

\subsubsection{Questioning Strategy}

Questioning Strategy is used to support students to evaluate their comprehension, to find alternatives, and to raise promising generalities when applying their knowledge freshly learned in class. Benchmarkeducaton (2011) stated that expert students are trained to question in terms of the content of material and elaborate their knowledge accordingly. Similarly, Collins and Smith (1982) explained that questioning strategy is used to correct misunderstandings in the reading of the text and in comprehension. However, Livingston (2003) observed that questioning strategy in reading is used to select cognitive knowledge for monitoring the metacognitive activity of reading and comprehension. Rawson, O'Neil, and Dunlosky (2011) suggested Self-analysis having twofold advantages that include:

1) It develops monitoring accuracy of students resulting effectively by controlling the learning and comprehension of the readers.

2) It improves recollection method for collecting or retaining previous concepts learned by readers to be used at the time of need correctly.

\subsubsection{Self-Regulating Strategy}

This approach denotes the capability of students to control their learning of reading and comprehension. According to Zimmerman and Pons (1986) Self-Regulating strategy involves actions directed towards certain goals of the students in order to obtain new knowledge in terms of better comprehension. Further, Gall, Gall, and Borg (2010) observed cognitive strategies and informed that these strategies develop text reading behavior of students and make them self-regulatory for using problem solving methods, self-evaluation, and self- control in learning. Similarly, Brown and Palincsar (1982) proposed two level of reading that includes:

1) Students read fast without any efforts without trying for comprehension the text.

2) Students read slowly and laboriously for better reading by monitoring the whole activity for excelling their comprehension.

However, Chapman (1993) suggested that active readers read slowly with great attention by applying different approaches of cognitive strategies in order to comprehend the material; this depends on individual dissimilarities in reading based on monitoring level.

\subsection{Evaluating as Metacognitive Strategy}

Evaluating plays a vital role in reading for several purposes. In a few words it is an art of judging the text for specific meaning to be utilized for certain objectives. Fries-Gaither (2012) proposed five important factors of evaluation in reading and comprehending material to determine readers with possibility of power in:

1) The importance attained from written manuscript

2) Accuracy in reading and credibility in comprehension

3) Appropriate material

4) Personal attachment with text for enjoyment

\section{5) Self progress in reading}

According to (Schiff \& Calif, 2004) evaluating is considered as a post-reading strategy that reveals the needs of students to summarize the core ideas for comprehension of certain material and to find supplementary evidences for outside needs. In addition, Benchmarkeducation (2011) informed that evaluating represents as a metacognitive process to judge the meaning of the text for using appropriately by fulfilling the needs of readers. This strategy helps readers to make suitable conclusion of the text and make a way to guess the meaning appropriately by planning for further reading strategies. Channa, Yossatorn and Yossiri (2012) investigated the attitudes of students towards activities used in classroom in Thailand. They found learners' perceptions and satisfactions on their teachers using class activities including teaching strategies, class activities and social environment. These strategies helped foreign learners studying in medical and engineering faculties reduced or changed negative attitudes. This study found promising outcomes of students' attitudes towards teacher using activities. Teachers are considered as reflective in terms of their pedagogy (Channa \& Nordin, 2014) to determine various practices for the learners belonging to different fields. The researchers identified cognitive learning methodologies and asserted as the input to design syllabus on reading comprehension. The researchers considered this study as the fundamental research in the domain of cognition, metacognition, and reading 
comprehension. Findings revealed that teacher's role is important to develop reading comprehension abilities of students as asserted by (Channa \& Nordin, 2014). Similarly, the teachers' perceptions towards English Language as medium of instructions were investigated by (Channa, 2012) in one university at Pakistan. The respondents of this study were the teachers teaching science subjects. The English was the medium of instruction of teachers carrying out classroom activities. The data was collected through observations and interviews. The finding showed that more than half of the participants considered English as a medium of instructions can develop students' abilities to meet their needs. However, less than half of the participants asserted local languages to be used as the medium for better comprehension. Further, researchers reviewed a study of needs, problems and wants of using English (Channa, Soranastaporn, Engchuan, \& Tirataradol, 2013) and investigated the needs of engineering students to use English by looking different problems in their academic and professional studies based on English language in order to explore students' wants of material to fulfill their needs. Similarly, another study investigated the engineering students' need to use English in Pakistan by (Channa, Soranastaporn, Engchuan, \& Tirataradol, 2013). The target population included two groups: fourth year engineering students (523) and engineering teachers (173), and the sample of this study included 217 students and 132 engineering teachers. The findings showed that both teachers and students found very extensive needs of language skills at their top priority. They needed more courses to design in order to meet their needs in terms of reading comprehension. In short, Channa and Nordin (2015) asserted that the performance in terms of reading comprehension can well be dazzling through reading practices of the students in class activities. The researchers highlighted the high dissatisfaction rate of reading comprehension seeing in a certain setting and proposed possible causes behind learners' poor performance based on the review of literature focusing the zone of proximal development and social cognitive theory as the possible solution for developing reading and comprehending reading materials in the progression of instructional practices.

\section{Summary and Conclusion}

Metacognitive learning procedures manage the utilization of the readers' held and put away information amid his mental learning methodology. They additionally empower the readers to utilize these procedures when confronting issues amid the reading procedure (Taboada, Biancob, \& Bowerman, 2012). Moreover, Young and Fry (2008) asserted that metacognitive encounters incorporate the methods of assessing and directing one's progressing comprehension and are not so much steady. The review of related suggests that metacognitive is partitioned into two angles:

1) Learning and Process: This area includes the appreciation of the motion of the brain particularly in the field of its capacity and the preparing.

2) Official Processes: This comprises of the act of arranging, observing, and directing in the manner of thinking. In this perspective, the interface between the reasoning personalities, which partners, makes and ponders, and the choice making personality, which makes the supervision, collaborates.

Additionally, metacognitive reading procedures are gifted used for observing, arranging and assessing the learning exercises. It is contended by Cook (1993) that metacognitive reading procedures are methods about adapting instead of learning techniques themselves. Also, Cook (1993) notices some metacognitive reading methodologies including selective attention, directed-attention, self-monitoring, self-reinforcement, and self-evaluation to be strengthened the reading nature of students.

\section{References}

Anderson, V. (1991). Training to foster active reading strategies in reading-disabled adolescents. Paper presented at the annual meeting of the American Educational Research Association, Chicago.

Ariel, R., Dunlosky, J., \& Bailey, H. (2009). Agenda-based regulation of study-time allocation: When agendas override item-based monitoring. Journal of Experimental Psychology: General, 138, 432-447. http://dx.doi.org/10.1037/a0015928

Baker, L., \& Brown, A. L. (1984). Metacognitive skills and reading. In P. D. Pearson (Ed.), Handbook of reading research (pp. 353-394).

Baker, L. (2002). Metacognitive comprehension instruction, In C. C. Block \& M. Pressley (Eds.), Comprehension instruction: research-based best practices (pp. 77-95), New York: Guilford.

Benchmarkeducation. (2011). Teaching resources-best practices: Metacognitive strategies, K-8. Retrieved from http://www.benchmarkeducation.com/educational-leader/reading/metacognitivestrategies.html

Block, E. (1986). The Comprehension Strategies of Second Language Readers. TESOL Quarterly, 20, 463-494. 
http://dx.doi.org/10.2307/3586295

Brown, A. L., \& Palincsar, A. S. (1987). Reciprocal teaching of comprehension skills: A natural history of one program for enhancing learning, In J. D. Day \& J. G. Borkowski (Eds.). Intelligence and exceptionality: New directions for theory, assessment, and instructional practices (pp. 81-131), Norwood, NJ: Ablex.

Brown, A. L., \& Palinscar, A. S. (1982). Inducing strategic learning from text by means of informed, self-control training. Topics in Learning and Learning Disabilities, 2(1), 1-17.

Boulware-Gooden, R., Carreker, S., Thornhill, A., \& Joshi, R. (2007). Instruction of metacognitive strategies enhances reading comprehension and vocabulary achievement of third-grade students. Reading Teacher, 61(1), 70-77. http://dx.doi.org/10.1598/RT.61.1.7

Channa, A. M, Yossatorn, Y., \& Yossiri, V. (2012). Students' Attitudes towards teachers' using Activities in EFL class. International Journal of Academic Research in Business and Social sciences, 2(5).

Channa, A. M., \& Nordin, Z. S. (2014). Identifying metacognitive strategies through learners' reading comprehension: A Review of related studies. Sci.Int. (Lahore), 26(5), 2457- 2460.

Channa, A. M. (2012). Teachers perceptions towards English language as a medium of instructions in Pakistan. Interdisciplinary Journal of Contemporary Research In Business, 4(5).

Channa, A. M., Soranastaporn, S., Engchuan, K. S., \& Tirataradol, Y. (2013). A study of needs, problems and wants of using English of Engineering students at Quaid-eAwam university of Engineering, Science and Technology, Pakistan. Journal of Education and Practice, 4(3).

Channa, A. M, Soranastaporn, S., Engchuan, K., \& Tirataradol, Y. (2013). A Study of Needs in Using English of Engineering Students at Quaid-E-Awam University of Engineering, Science and Technology, Pakistan. Journal of Thonburi University, 7(14), 9-19.

Channa, A. M., \& Nordin, Z. S. (2015). Social cognitive theory and the zone of proximal development in the learning of reading comprehension. Sci. Int. (Lahore), 27(1), 581-585.

Cook, V. (1993). Linguistics and Second Language Acquisition. London: Macmillan.

Chapman, A. (1993). Making sense: Teaching critical reading across the curriculum. New York: College Entrance Examination Board.

Collins, A., \& Smith, E. E. (1982). Teaching the process of reading comprehension. In D. K. Detterman \& R. J. Sternberg (Eds.). How and how much can intelligence be increased (pp. 173-185). Norwood, NJ: Ablex.

Flavel J. H., (1976). Metacognitive aspects of problem solving. In L .B. Resnick (Ed.). The nature of intelligence (pp. 231-236). Hillsdale, NJ: Erlbaum.

Flavell, J. H., (1979). Metacognition and cognitive monitoring. American Psychologist, 34, 906-911. http://dx.doi.org/10.1037/0003-066X.34.10.906

Flavell, J. H. (2004). Theory-of-mind development: Retrospect and prospect. Merrill-Palmer Quarterly, 50, 274-290. http://dx.doi.org/10.1353/mpq.2004.0018

Fries-Gaither, J. (2012). Evaluating in reading and science. Beyond Weather and the Water Cycle. Retrieved from http://beyondweather.ehe.osu.edu/issue/we-study-earths-climate/evaluating-inreading-and-science

Gall, J., Gall, M., \& Borg, W. (2010). Applying educational research. 6th. Boston, MA: Pearson.

Livingston, J. A. (2003). Metacognition: An overview. (ERIC Document Service No. ED 414273).

Newell, A., \& Simon, J. A. (1972). Human problem solving. Englewood Cliffs, NJ: Prentice-Hall.

Piaget, J. (1971). The construction of reality in the child (2nd ed.), New York: Ballantine.

Rosenshine, B. B., \& Meister, C. C. (1992). The use of scaffolds for teaching higher-level cognitive strategies. Educational Leadership, 49(7), 26.

Rawson, K. A., O’Neil, R., \& Dunlosky, J. (2011). Accurate monitoring leads to effective control and greater learning of patient education materials. Journal of Experimental Psychology: Applied, 17(3), 288-302. http://dx.doi.org/10.1037/a0024749

Schiff, R., \& Calif, S. (2004). An academic intervention program for EFL university students with reading disabilities. Journal of Adolescent and Adult Literacy, 48(2), 102-113. http://dx.doi.org/ 10.1598/JAAL.48.2.2 
Son, L. K. (2005). Metacognitive control: Children's short-term versus long-term study strategies. Journal of General Psychology, 132, 347-363. http://dx.doi.org/10.3200/GENP.132.4.347-364

Taboada, A., Biancob, S., \& Bowerman, V. (2012). Text-based questioning: A comprehension strategy to build English language learners' content knowledge. Literacy Research and Instruction, 51, 87-109. http://dx.doi.org/10.1080/19388071.2010.522884

Tarricone, P. (2011). The taxonomy of metacognition. Hove, UK: Psychology Press.

Thiede, K. W., Anderson, M. C. M., \& Therriault, D. (2003). Accuracy of metacognitive monitoring affects learning of texts. Journal of Educational Psychology, 95, 66-75. http://dx.doi.org/10.1037/0022-0663.95.1.66

Vygotsky, L. (1978). The mind in society, Cambridge, MA: Harvard University Press. (Original work published 1938)

Young, A., \& Fry, J. D. (2008). Metacognitive awareness and academic achievement in college students. Journal of the Scholarship of Teaching and Learning, 8(2), 1-10.

Zimmerman, B. J., \& Moylan, A. R. (2009). Self-regulation: Where metacognition and motivation intersect. In D. J. Hacker, J. Dunlosky \& A. C. Graesser (Eds.). Handbook of metacognition in education (pp. 299-316). New York: Routledge.

Zimmerman, B. J., \& Pons, M. M. (1986). Development of a structured interview for assessing student use of self-regulated learning strategies. American Educational Research Journal, 23(4), 614-628. http://dx.doi.org/10.3102/00028312023004614

Zimmerman, B. J. (2008). Goal setting: A key proactive source of academic selfregulation. In D. H. Schunk, B. J. Zimmerman (Eds.). Motivation self-regulated learning: Theory, research, and applications (pp. 267-295). US: Lawrence Erlbaum Associates Publishers.

\section{Copyrights}

Copyright for this article is retained by the author(s), with first publication rights granted to the journal.

This is an open-access article distributed under the terms and conditions of the Creative Commons Attribution license (http://creativecommons.org/licenses/by/3.0/). 